http://jmscr.igmpublication.org/home/ ISSN (e)-2347-176x ISSN (p) 2455-0450

crossref DOI: https://dx.doi.org/10.18535/jmscr/v10i1.11

\author{
Journal Of Medical Science And Clinical Research \\ IGM Publication \\ An official Publication of IGM Publication
}

\title{
Predictors of steroid dependency in Indian children with Idiopathic Nephrotic Syndrome
}

\author{
Authors \\ Sreekanth Sagar ${ }^{1}$, Bindu Sarojam ${ }^{2 *}$, Geetha Saradakkutty ${ }^{3}$, Susan Uthup $^{4}$ \\ ${ }^{1}$ MD Pediatrics, Department of Pediatrics, SAT Hospital, Govt. Medical College, Thiruvananthapuram, Kerala \\ ${ }^{2}$ MD Pediatrics, Department of Pediatrics, SAT Hospital, Govt. Medical College, Thiruvananthapuram, Kerala \\ ${ }^{3}$ MD Pediatrics, M Phil Epidemiology, Department of Pediatrics, SAT Hospital, Govt. Medical College, \\ Thiruvananthapuram, Kerala \\ ${ }^{4}$ DM Nephrology, Department of Pediatric Nephrology, SAT Hospital, Govt. Medical College Thiruvananthapuram, \\ Kerala \\ *Corresponding Author \\ Bindu Sarojam MD Pediatrics \\ Department of Pediatrics, SAT Hospital, Govt. Medical College, Thiruvananthapuram, Kerala, India
}

\begin{abstract}
Introduction: Idiopathic nephrotic syndrome is the commonest glomerular disease in children. Relapses are common and 50\% with multiple relapses become steroid dependent requiring prolonged immunosuppressive treatment.

Methods: A hospital based prospective follow up study with nested case control design was conducted in children with first episode of Idiopathic Nephrotic syndrome to determine predictive risk factors for steroid dependency. Age at onset, birth weight, concurrent respiratory tract infections, hematuria at onset, hypertension and time to remission were assessed as predictive risk factors for dependency.

Results: 146 children were recruited. After excluding 6 steroid resistant ones, 137 were followed up for one year.14.5\%[20] children became steroid dependent, 54.7\% [75] had infrequent relapses and 30.65\% [42] had no relapses. Small for gestational age (SGA),[P 0.000, OR 7.59, 95\% CI 2.72 - 21.17], more than 10 days to attain remission [P 0.000, OR 7.19, 95\% CI 2.58-20.0] and concurrent upper respiratory tract infection during relapses $x z[P$ 0.000, OR 6.88, 95\% CI 2.16 - 21.92] were significant factors associated with steroid dependence. The area under an ROC curve plotted to evaluate the prediction model based on the time to attain remission (more than 10 days) showed 0.792 (95\% CI $0.678-0.906$ ).

Conclusion: Time to remission of more than 10 days, concomitant respiratory tract infections with relapse and being SGA were significant predictors for development of steroid dependence. Identification of children at risk for dependency at onset will help in counseling and planning treatment strategies avoiding drug toxicity and reducing morbidity.

Keywords: Nephrotic Syndrome; Remission, Relapses, Dependence.
\end{abstract}

\section{Introduction}

Nephrotic syndrome is the commonest glomerular disease in children with an annual incidence of 1.3-3 new cases per 100,000 population ${ }^{[1]}$.
Minimal change nephrotic syndrome (MCNS) is the most common cause of idiopathic nephrotic syndrome in children, with a $2: 1$ predilection for boys $^{1,2,3}$. About $90 \%$ of children with MCNS will 
respond well to steroid treatment ${ }^{4}$. However, the rate of relapse is high $(60 \%-75 \%)$, with half of those relapsing eventually becoming steroid dependent ${ }^{5,6}$. Frequent or continuous administration of steroids and stepwise increase in immunosuppression is often needed in frequent relapsers and steroid dependent. These children will be at risk of treatment related complications like cumulative steroid toxicity, posterior subcapsular cataracts, short stature and susceptibility to infections ${ }^{2}$. Identification of children at risk for dependency at onset will help in counseling and planning treatment strategies avoiding drug toxicity and reducing morbidity ${ }^{5,6}$. The predictors of steroid dependency in various studies from across the world are gender, age at onset, duration from initial steroid therapy to response and, concomitant upper respiratory tract infection during relapse, steroid regimen used and time to first relapse $\mathrm{e}^{7,8,9,10,11,12}$. There is paucity of data on pattern of steroid dependence in children from south India. We thus planned a study to determine the risk factors for the development of steroid dependency in first episode of Idiopathic Nephrotic syndrome in children from South India.

\section{Methods}

A nested case control Study was conducted on prospectively followed up children with first episode of idiopathic nephrotic syndrome in a tertiary care teaching hospital in South India for a period of 2 years to identify predictors for development of steroid dependency. Ethical committee clearance was obtained from the human ethical committee and informed consent was obtained from the study subjects. The diagnosis of idiopathic nephrotic syndrome was based on clinical presentation, confirmed by urinalysis and blood investigations as per the ISPN guidelines ${ }^{13}$. Steroid dependence was defined as two consecutive relapses occurring while the patient is on alternate day steroid therapy or within 14 days of stopping steroid therapy. Absence of remission even after 4 weeks of adequate daily standard dose steroid therapy was defined as resistance ${ }^{13}$.

Sample size was determined using a case control design. The predictive variable which has least prevalence among control group was taken for estimation of sample size ( $\alpha$ error 0.05 and $80 \%$ power)

$$
n=\left(\frac{r+1}{r}\right) \frac{(\bar{p})(1-\bar{p})\left(Z_{\beta}+Z_{\alpha / 2}\right)^{2}}{\left(p_{1}-p_{2}\right)^{2}}
$$

$\mathrm{n}$ = sample size in the case group

$\mathrm{r}=$ ratio of controls to cases

$(\bar{p})=$ measure of variability

$\mathrm{Z}_{\beta}=$ desired power [typically 0.84 for $80 \%$ power]

$Z_{\alpha / 2}=$ desired level of statistical significance [typically 1.96]

$\mathrm{p}_{1}=$ remission not attained even after 14 days of therapy in controls $[30 \%]^{14}$

$\mathrm{p}_{2}=$ remission not attained even after 14 days of therapy in cases $[64.8 \%]^{\mathbf{1 4}}$. Number of cases was 20. Ratio between controls and cases was taken as $5: 1^{14}$.

All children admitted as first episode of idiopathic nephrotic syndrome with onset above 1 year during a two year period were included in the study. Children with congenital and secondary nephrotic syndrome were excluded. Those children who failed to respond to steroids and with incomplete follow up were excluded from analysis. Clinical characteristics like age at onset, gender, birth weight, microscopic hematuria at onset and hypertension were collected. Treatment was given as per the IPNG protocol $^{13}$. The number of days taken to achieve remission was noted. Children were kept under periodic follow up till one year and the details of relapses including number of relapses, concurrent respiratory tract infections and complications were recorded. The outcome assessed was occurrence of steroid dependence in responders. For the nested case control study cases \& controls were defined as follows: Steroid responders who later 
developed steroid dependence were cases and who did not develop steroid dependence were the controls.

SPSS for windows [version 25) was used for statistical analysis. Base line characteristics of the study participants were expressed as mean+/-2SD and percentage. Chi-square test and Fischer's Exact Test were used for comparison of qualitative variables. Intergroup comparisons of quantitative variables were made by using paired and unpaired student's $t$ test. $P$ value $<0.05$ was considered significant. Analysis of risk factors for steroid dependence was done by Univariate analysis. Multivariate analysis was done to predict steroid dependency based on the clinical profile and time to remission The time taken for remission was further analyzed in order to determine a cut-off duration beyond which a significant risk of steroid dependency would be present. An ROC curve was plotted to evaluate the performance of the prediction modelbased on the days taken to attain remission during the initial episode.

\section{Results}

146 children above the age of one year admitted with first episode of idiopathic nephrotic syndrome during the period of January 2014 to January 2016 were recruited for study. Minimum follow up was 1 year and maximum 3 years. 3 children were lost to follow up and 6 children became steroid resistant. Of the 137 children followed up, there were 84 [61.3\%] males and 53[38.6\%] females (male to female ratio 1.58:1).The characteristics of the study population is given in Table 1.20 steroid dependent (14.59\%)children formed cases and the rest 117 formed the controls.

Of the 137 children followed up, 42 [30.65\%] had no further relapses and 75 [54.7\%] were infrequent relapsers. Mean age of presentation of the dependent group was $5.4 \pm 2.8$ years and non dependent groupwas $4.7 \pm 2.8$ years. There was no statistically significant difference between age at presentation or gender and steroid dependence.7.6
$\%$ (2) of children below 2 years and $16.2 \%$ (18) above 2 years became steroid dependent. There was no significant difference in the occurrence of steroid dependence and age above or below 2 years (P 0.364).

37 children were born small for gestational age (SGA).65\% of children with dependence were born SGA while $20.5 \%$ were born SGA in in the non-dependent group and this association was significant [OR- 7.19, 95\% CI 2.58 - 20.00]. There was no significant association between steroid dependency and micro hematuria or hypertension in the initial episode. The mean serum albumin and serum cholesterol were similar in the two groups. The mean time to remission in steroid dependent group (20) and non-dependent group (117)was 10.05(2.41) and 7.35(2.41) respectively. The difference was statistically significant ( $p$ 0.00). By univariate analysis, small for gestational age at birth, time to remission in first episode, number of relapses, relapses with upper respiratory infection were the significant factors associated with steroid dependence (Table 2) .

$80 \%$ of dependent children $(16 / 20)$ had relapse with concomitant respiratory tract infections while $36.7 \%$ (43/117) of nondependent group had relapses with respiratory tract infections. This association was statistically significant $(P=0.001$, $\mathrm{OR}=12.58$, 95\% CI 2.95-53.6). Mean number of relapses over one year was significantly high in steroid dependent group 4.35(0.87) as compared to $1.12(1.0)$ in the other group.

Time to remission more than 10 days or more $(P=0.001, \quad$ OR $=9.06,95 \%$ CI $2.55-32.13)$, concomitant respiratory tract infections during relapses $(P=0.001, \mathrm{OR}=12.58,95 \%$ CI $2.95-53.6)$ and small for gestational age children (P0.000, OR10.05, 95\% CI 2.76 - 36.59) were significant predictors for development of steroid dependence by multivariate analysis (Table 3 ).

Time taken for remission during the initial episode of nephrotic syndrome was further analyzed to determine a cut-off duration beyond which steroid dependency would be present. After stratifying patients according to different cut-off times to 
remission, an initial remission duration of 10 days or longer was found to be significantly associated with steroid dependency. $65 \%$ of children who had not achieved remission by day 10 of steroid treatment became steroid dependent. This percentage increased with each extra day and reached $100 \%$ by day 14 .Those who achieved remission after 10 days during the initial episode were steroid dependent $(65.0 \%$ sensitivity and $80.3 \%$ specificity with an accuracy of $78.1 \%$ ). AnROC curve was plotted to evaluate the days to attain remission during the initial episode. The area under the ROC curve was 0.792 with $95 \%$ CI $(0.678-0.906)$ (Figure 1).

Table 1 Characteristics of Study population

\begin{tabular}{|l|c|c|c|}
\hline Patient profile & $\begin{array}{c}\text { Cases } \\
\mathrm{n}=20\end{array}$ & $\begin{array}{c}\text { Controls } \\
\mathrm{n}=117\end{array}$ & P value \\
\hline M:F ratio & $3: 1$ & $1.4: 1$ & 0.17 \\
\hline Age mean(SD) & $5.36(2.84)$ & $4.73(2.8)$ & 0.35 \\
\hline SGA & 13 & 24 & 0.00 \\
\hline Hematuria & 0 & 9 & 0.35 \\
\hline Hypertension & 1 & 8 & 0.75 \\
\hline Total Protein & $4.26(0.36)$ & $4.30(0.62)$ & 0.76 \\
\hline S albumin mean(SD) & $1.95(0.25)$ & $1.87(0.39)$ & 0.41 \\
\hline S cholesterol mean(SD) & $409.5(120.09)$ & $402.16(115.31)$ & 0.79 \\
\hline Time to remission mean(SD) & $10.05(2.41)$ & $7.35(2.41)$ & 0.00 \\
\hline Concomitant URI & $1.2(0.41)$ & $1.63(0.48)$ & 0.00 \\
\hline Total relapses & $4.35(0.85)$ & $1.12(1.001)$ & 0.00 \\
\hline
\end{tabular}

Table 2 Risk factors associated with steroid dependency -Univariate Analysis

\begin{tabular}{|c|c|c|c|c|c|}
\hline \multicolumn{2}{|l|}{ Parameter } & SDNS & No dependency & P value & Odds ratio \\
\hline \multirow[t]{2}{*}{ Age } & $<2$ years & $2(7.6)$ & $24(92.4)$ & \multirow[b]{2}{*}{0.364} & \multirow{2}{*}{$\begin{array}{c}2.20 \\
(0.47-10.17)\end{array}$} \\
\hline & $>2$ years & $18(16.2)$ & $93(83.8)$ & & \\
\hline \multirow[t]{2}{*}{ Sex } & Male & $15(17.9)$ & $69(82.1)$ & \multirow[t]{2}{*}{0.174} & \multirow{2}{*}{$\begin{array}{c}9.06 \\
(2.55-32.13)\end{array}$} \\
\hline & Female & $5(9.4)$ & $48(90.6)$ & & \\
\hline \multirow[t]{2}{*}{ Birth weight } & SGA & $13(35.1)$ & $24(64.9)$ & \multirow[b]{2}{*}{0.000} & \multirow{2}{*}{$\begin{array}{l}\text { 7. } 19(2.58- \\
20.00)\end{array}$} \\
\hline & AGA & $7(7.0)$ & $93(93.0)$ & & \\
\hline \multirow{2}{*}{$\begin{array}{ll}\text { Days } & \text { for } \\
\text { remission } & \end{array}$} & $<10$ days & $7(6.9)$ & $94(93.1$ & \multirow[b]{2}{*}{0.000} & \multirow{2}{*}{$\begin{array}{c}7.59 \\
(2.72-21.17) \\
\end{array}$} \\
\hline & $>10$ days & $13(36.1)$ & $23(63.9)$ & & \\
\hline \multirow{2}{*}{$\begin{array}{l}\text { Relapses with } \\
\text { URI }\end{array}$} & Yes & $16(27.1)$ & $43(72.9)$ & \multirow[b]{2}{*}{0.000} & \multirow{2}{*}{$\begin{array}{c}6.88 \\
(2.16-21.92)\end{array}$} \\
\hline & No & $4(5.1)$ & $74(94.9)$ & & \\
\hline \multirow[t]{2}{*}{ Hematuria } & Yes & $0(0)$ & $9(100)$ & \multirow[b]{2}{*}{0.231} & \multirow[b]{2}{*}{-} \\
\hline & No & $20(15.6)$ & $108(84.4)$ & & \\
\hline \multirow[t]{2}{*}{ Hypertension } & Yes & $1(11.1)$ & $8(88.9)$ & \multirow[b]{2}{*}{0.611} & \multirow{2}{*}{$\begin{array}{c}5.63 \\
(0.33-93.9)\end{array}$} \\
\hline & No & $1914.5)$ & $109(85.2)$ & & \\
\hline
\end{tabular}

Table 3 Multivariate Logistic regression analysis to assess the risk factors for steroid dependency

\begin{tabular}{|l|c|c|c|}
\hline Parameter & Variable & $\mathbf{p}$ & $\begin{array}{c}\text { Odds Ratio } \\
\text { (95\% CI) }\end{array}$ \\
\hline Days for remission & $<10$ Days & 0.001 & $\begin{array}{c}9.06 \\
(2.55-32.13)\end{array}$ \\
\cline { 2 - 2 } & $>10$ Days & & $\begin{array}{c}10.05 \\
(2.76-36.59)\end{array}$ \\
\hline \multirow{2}{*}{ Birth weight } & SGA & \multirow{2}{*}{0.000} & $\begin{array}{c}12.58 \\
\end{array}$ \\
\cline { 2 - 2 } & AGA & & $(2.95-53.6)$ \\
\cline { 2 - 2 } & Yes & 0.000 & \\
\hline
\end{tabular}


Figure 1

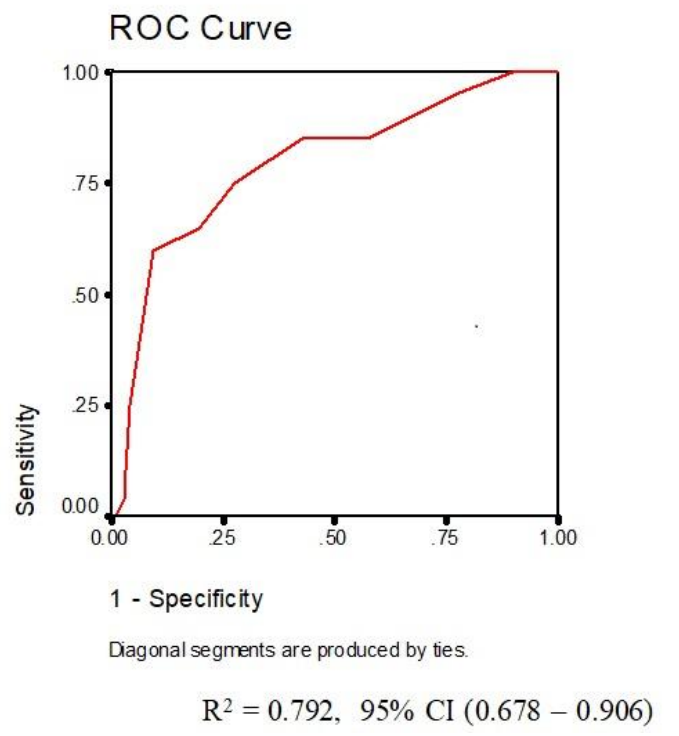

ROC curve - Days to remission in predicting Steroid dependency

\section{Discussion}

Although idiopathic nephrotic syndrome in children is eminently treatable with good long term outcome, the rate of relapse is high $(60 \%-$ $75 \%$ ), with half of those relapsing eventually becoming steroid dependent ${ }^{5,6}$.Steroid dependency and frequent relapses pose definite risk for drug toxicity ${ }^{15}$. Identification of children at risk for dependency early in the course of the disease will help in alerting the attending clinician to the need for close monitoring, initiating treatment with steroid-sparing agents ${ }^{15}$, including levamisole, cyclophosphamide, mycophenolate mofetil, cyclosporine A (CyA) or tacrolimus ${ }^{16,17}$ and rituximab ${ }^{18,19,20}$ and counseling the family for frequent followup.

Indian study by Gulati et al in 116 children with idiopathic nephritic syndrome reported dependency in $18,1 \%{ }^{21}$. In our study $14.5 \%$ of children were steroid dependent. In our study the male is to female ratio in dependent children was 3:1 and nondependent group was 1.4:1.This was similar to other studies which showed that nephrotic syndrome is about twice as prevalent in boys $^{2,6,14}$.There was no significant association between gender and steroid dependency in our study.
The mean age of presentation of steroid dependent group was $5.36 \pm 2.8$ years and of the non-steroid dependent group was $4.73 \pm 2.8$ years. There was no significant association with age at onset of the nephrotic syndrome, though earlier studies have shown an increase of steroid dependency with age $^{9,22,23}$.

SGA babies are at high risk for renal diseases due to reduced nephron endowment. Nephrotic children who are born SGA are at increased risk for difficult and prolonged course with dependency, higher relapse rate and late steroid resistance. In this study $65 \%$ of children with steroid dependence were born SGA when compared with $20.5 \%$ in other group. There was significant association between development of steroid dependence and SGA [OR- 7.19, 95\% CI 2.58 - 20.00]. Several studies have shown that LBW and IUGR are associated with a steroiddependent and steroid resistant course of nephrotic syndrome ${ }^{24,25}$. Compared with normal birth weight, children with LBW will have complicated long term clinical course with more relapses, higher cumulative steroid requirement and higher need for second line immunosuppressive agents. Glomerular hyper filtration due to low nephron endowment possibly increases the risk in SGA babies for a complicated course.

Similar to the observations in other studies, microscopichematuria and hypertension during the initial episode were not found to be associated with steroid dependence in our study ${ }^{(26)}$.

The time to remission from the start of steroid therapy is an accurate early prognostic factor in predicting the outcome ${ }^{6,7,10,26}$. In a study from Egypt, children who did not achieve remission by day 20 of the initial prednisone course became steroid dependent (96\% specificity, 50\% sensitivity) ${ }^{27}$. In our study, children who had not achieved remission by the 10th day of steroid treatment, $65 \%$ became steroid dependent. This percentage increased with each extra day until it reached $100 \%$ by day 14 . An ROC curve was plotted based on the days taken for attaining 
remission in the initial episode and the area under the curve was 0.792 with[ $95 \%$ CI 0.678 0.906] (Figure 1).

Patients with frequent respiratory infection associated relapses of MCNS may develop steroid dependency $^{23,26}$. Conversely, those patients who do not relapse during episodes of respiratory tract infection might be less likely to be steroid dependent. In the present study a significant association was found between respiratory infections induced relapses and steroid dependency.

In a study by Takeda et al. gender, age at onset, duration of illness, prednisolone dosage at the most-recent relapse, and regimens of initial steroid therapy were not associated with risk for development of dependency. Relapse within the first year was a powerful independent predictor of subsequent relapse irrespective of the duration of illness ${ }^{26}$.In our study also age of onset and gender had no significant association with development of steroid dependence. Mean number of relapses were significantly higher in the dependent group (P 0.000).

The retrospective analysis by Mishra K et al have shown that adequate treatment ( $\geq 12$ weeks) of was associated with less chance of frequent relapses and steroid dependence. Also occurrence of first relapse occurring within 5.5 months predicted a frequently relapsing or steroid dependent course $^{(8)}$. Ours was a prospective study and all children received the standard 12 weeks steroid treatment as per the ISPN guidelines. In this study we have not analyzed relapses within first year of onset as a predictor for dependency.

Multivariate logistic regression analysis showed that time to attain remission more than 10 days ( $p$ $0.001, \mathrm{OR}=9.06,95 \%$ CI $2.55-32.13$ ) and concomitant respiratory tract infections during relapses $(p 0.001, \mathrm{OR}=12.58,95 \%$ CI $2.95-53.6)$ and small for gestational age ( $\mathrm{p} 0.000, \mathrm{OR}=$ $10.05,95 \%$ CI 2.76 - 36.59) were significantly associated with the development of steroid dependency. In a similar study by Kim Yap et al, $61.5 \%$ of the 91 children became steroid dependent and attainment of remission in the first episode after 9 days of steroid initiation and concomitant URTI during subsequent relapses were significant predictors of steroid dependency by both univariate and logistic regression analyses $^{14}$. Higher percentage of dependency reported by Kim Yap et al may be due to the fact that their study was in a dedicated Pediatric Nephrology referral unit while our study was done in a Pediatric referral hospital.

\section{Conclusion}

INS in children is essentially a benign disease that responds well to steroids. Though the prognosis is mostly favorable, steroid dependency poses major problems in the management. Time to remission less than 10 days, being SGA and concurrent infection can predict steroid dependency. This helps to counsel families, ensure close follow up, plan long-term management reducing relapses and drug toxicity.

\section{Limitations}

Short follow up of one year and limited number of study subjects is the main limitation. Also we have not assessed time to first relapse as a factor associated with steroid dependency.

\section{Conflict of Interest- None \\ Source of Funding -Nil}

\section{References}

1. Chesney RW (1999) Idiopathic nephrotic syndrome. Curr Opin Pediatr 11:158-161

2. Robson WL, Leung AK (1993) Nephrotic syndrome in childhood. Adv Pediatr 40:287-323

3. International Study of Kidney Diseases in Children (1981).The primary nephrotic syndrome in children: identification of patients with minimal change nephrotic syndrome from initial response to prednisone. J Pediatr 98:561-564

4. Andenmatten F, Bianchetti MG, Gerber HA, Zimmermann A,Meregalli P, Luthy 
C, Oetliker OH (1995) Outcome in idiopathic childhood nephrotic syndrome. Scand J Urol Nephrol29:15-19

5. Bargman JM (1999) Management of minimal lesion glomerulonephritis: evidence-based recommendations. KidneyInt 55[Suppl 70]:S3-S16

6. Constantinescu AR, Weiss LS et al (2000) Predicting first-year relapsers in children with nephrotic syndrome. Pediatrics 105:492-495

7. Vivarelli M, Moscaritolo E, Tsalkidis A, Massella L, Emma F. Time for initial response to steroids is a prognostic factor in idiopathic nephrotic syndrome. J Pediatr. 2010;156: 965-97

8. Mishra K, Kanwal SK, Sajjan SV, Bhaskar $\mathrm{V}$, Rath B. Predictors of poor outcome in children with steroid sensitive nephrotic syndrome. Nefrologia. 2018 Jul-Aug; 38(4):420-424.

9. AditiSinha, Panka jHari, Piyush Kumar Sharma. Disease Course in Steroid Sensitive Nephrotic Syndrome Indian Pediatr 2012; 49: 881-887

10. Dawman L, Mehta, A., Sharawat I.K. . Risk Factors for Steroid Dependency in Children with Idiopathic Nephrotic Syndrome in India. Indian J Pediatr 83, 261 (2016). https://doi.org/10.1007/s12098-015-1819$\mathrm{y}$

11. Agarwal, N., Abhinay, A., Mishra, R.N. et al. Validation of Predictors of Relapse in Steroid Sensitive Idiopathic Nephrotic Syndrome. Indian J Pediatr 85, 570-571 (2018). https://doi.org/10.1007/s12098018-2656-6

12. Dakshayani B, Premalatha $R$ et al . Predictors of frequent relapsing and steroid-dependent nephrotic syndrome in children. Turk PediatriArs 2018: 53: 2430.

13. Uma Ali, arvind Bagga, S. Banerjee, Madhuri Kanitkar, K.D. Phadke, P.
Senguttuvan, S.K. Sethi and Mehul Shah. Revised guidelines for management of steroid sensitive nephrotic syndrome. Indian Journal of Nephrology Jan 2008/ Vol18/ Issue 1

14. Yap HK, Han EJ, Heng CK, Gong WK (2001) Risk factors for steroid dependency in children with idiopathic nephrotic syndrome. PediatrNephrol 16:1049-1052

15. Pravitsitthikul N, Hodson EM, Craig JC (2013)

Non-corticosteroid immunosuppressive medications for steroid-sensitive nephrotic syndrome in children. Cochrane Database Syst Rev 10:CD002290

16. Sinha MD, MacLeod R, Rigby E, Clark AG (2006) Treatment of severe steroiddependent nephrotic syndrome (SDNS) in children with tacrolimus. Nephrol Dial Transplant 21:1848-185

17. Loeffler K, Gowrishankar M, Yiu V (2004) Tacrolimus therapy in pediatric patients with treatment-resistant nephrotic syndrome. PediatrNephrol 19:281-287

18. Benz K, Dotsch J, Rascher W, Stachel D (2004) Change of the course of steroiddependent nephrotic syndrome after rituximab therapy. Pediatr Nephrol 19:794-797

19. Hodson EM, Craig JC (2014) Rituximab for childhood-onset nephrotic syndrome. Lancet 384(9950):1242-1243

20. Ravani P, Ponticelli A, Siciliano C, et al : Rituximab is a safe and effective longterm treatment for children with steroid and calcineurin inhibitor-dependent idiopathic nephrotic syndrome. Kidney Int. 2013;84(5):1025-33. 10.1038/ki.2013.211

21. Gulati S, Kher V, Sharma RK, Gupta A. Steroid response pattern in Indian children with nephrotic syndrome. Acta Pædiatr 1994;83:530-3

22. Kabuki N, Okugawa T, Hayakawa H, Tomizawa S, Kasahara T, Uchiyama M (1998) Influence of age at onset on the 
outcome of steroid-sensitive nephrotic syndrome. Pediatr Nephrol 12:467-470

23. Cornfield D, Schwartz MW (1966) Nephrosis: a long term study of children treated with corticosteroids. J Pediatr 68:507-515

24. Nynke Teeninga, Michiel F. Schreuder et al. Influence of low birth weight on minimal change nephrotic syndrome in children, including a meta-analysis Nephrol Dial Transplant (2007) 0: 1-6 doi: 10.1093/ndt/gfm829

25. N Konstantelos et al .Association of low birth weight and prematurity with clinical outcomes of childhood nephrotic syndrome: a prospective cohort study. 2019Pediatric Nephrology 34(9) DOI: 10.1007/s00467-019-04255-1

26. A. Takeda, Masuhiro Simoda et al ; Prediction of subsequent relapse in children with steroid-sensitive nephrotic syndrome Pediatric Nephrology 2001, Volume 16, Issue 11, pp 888-893

27. Maher Ahmed Abdel-Hafez, Nagy Mohamed Abou-El-Hana, Adel Ali Erfan, Mohamed El-Gamasy, Hend Abdel-Nabi. Predictive risk factors of steroid dependent nephrotic syndrome in children. $\mathbf{J}$ Nephropathol. 2017;6(3):180-186. 